\title{
Nematotoxic effects of endophyte-infected tall fescue toxins and extracts in an in vitro bioassay using the nematode Pratylenchus scribneri
}

\author{
A.A. BACETTY ${ }^{1}$, M.E. SNOOK ${ }^{1}$, A.E. GLENN ${ }^{1}$, C.W. BACON ${ }^{1}$, \\ P. NAGABHYRU ${ }^{2}$ and C.L. SCHARDL ${ }^{2}$ \\ ${ }^{1}$ Toxicology and Mycotoxin Research Unit, USDA, ARS, Russell Research Center, Athens, GA. 30604 USA \\ ${ }^{2}$ Department of Plant Pathology, University of Kentucky, Lexington, KY. USA \\ charles.bacon@ars.usda.gov
}

\begin{abstract}
Biotypes of the Neotyphodium coenophialum-tall fescue grass symbiota are provided with enhanced protection from grazing vertebrate herbivores due to the production of toxic secondary metabolites. However, considerable controversy exists concerning this symbiotum and its toxicity to nematode species. A sterile in vitro system was developed to determine the interactive nature of known toxins specific to this mutualistic association and compounds within grass extracts known to be nematotoxic. The in vitro assay used Pratylenchus scribneri, the lesion nematode, as the target organism to determine the interactive nature of ergot alkaloids, the pyrrolizidine alkaloid (the lolines), total phenolic fractions, and specific phenolic compounds. The in vitro assay is described along with methods for testing toxicity. The results indicate that only two of three ergot alkaloids were toxic to $P$. scribneri, and there were possible potentiating or synergistic effects with other alkaloids and water soluble polyphenolics. HPLC analysis and UV mass spectrometry of root extracts revealed the presence of two major polyphenolics, chlorogenic and di-caffeoylquinic acids, both of which are natural constituents of this and other plants and have known toxicity to several species of nematodes. Further, it was determined that there were quantitative differences between the total phenolic and specific phenolic contents in roots of endophyte infected and noninfected tall fescue, cultivar Jesup. This in vitro assay offers a rapid and routine screen for acute testing chemical components of the tall fescue-endophyte symbiotum for toxicity to this nematode species.
\end{abstract}

Keywords: Chlorogenic acid, di-caffeoylquinic acids, ergot alkaloid, lolines, nematode, polyphenolics, Pratylenchus scribneri, pyrrolizidine alkaloid

\section{Introduction}

Biotypes of Neotyphodium-tall fescue grass symbiota are provided with enhanced protection from grazing vertebrate herbivores and insects due to the production of toxic secondary metabolites. However, considerable controversy exists concerning the involvement of the Neotyphodium coenophialum and resulting toxicity to nematode species. Early observations indicated possible resistance of Kentucky-31 to several species of nematodes (McGowan et al. 1961; Hoveland et al. 1975; Pedersen et al. 1988). These early observations have been substantiated for some nematode species (Pederson \& RodriguezKabana 1984; Townsend et al. 1984; West et al. 1988; Halisky \& Myers 1989; West et al. 1990), although the chemical identity of repelling toxins remain unknown or not clearly established. Identifying the chemical agent or agents responsible for any and all nematocidal responses, particularly as it relates to the fungus, is highly desirable. Ultimately the chemical identities should indicate any fungal contribution from the symbiotum components, or any interactive relationship with the host grass for increased toxicity. This approach may also determine if the livestock toxins are distinct or synergistic with specific nematotoxic compounds. Additionally, such a system should also have the potential for rapidly identifying native and novel strains of $N$. coenophialum that are more aggressive to species of nematodes, hopefully extending control across the many trophic species of these obnoxious plant pathogens. The outcome will provide a focus for technological exploitations of forage grasses for nematode resistance. However, a rapid and routine technique is required to identify the substance or substances responsible for nematotoxic biological activity in symbiotic tall fescue and other symbiota.

We describe here a sterile in vitro system developed to determine the interactive nature of known toxins specific to the tall fescue mutualistic association and compounds known to be nematotoxic in plants. This bioassay was used successfully to determine the toxicity of several classes of mycotoxins to several species of nematodes (Ciancio 1995; Nitao et al. 1999; Nitao et al. 2001). The in vitro assay system developed used the lesion nematode Pratylenchus scribneri as the target organism to determine the interactive nature of the test compounds, which include the ergot alkaloids, the pyrrolizidine alkaloid (the lolines), and extracts and fractions from roots of tall fescue.

\section{Materials and Methods}

\section{Pratylenchus scribneri nematode bioassay}

Bioassays were conducted under sterile in vitro conditions following the procedure of Meyer et al. (1990). Briefly, it consisted of testing purified compounds as well as total root extracts and fractions of endophyte-infected and non-infected tall fescue cv. Jessup on the mobility of second-stage juveniles (J2) of P. scribneri (Fig. 1). Harvested eggs of P. scribneri were

Figure 1 Procedure of the In vitro Bioassay used for detecting antagonism of extracts and compounds from endophyte/tall fescue to the lesion nematode Pratylenchus scribneri (see text for specific details)

Nematodes grown on sterile root explants

1. Mixed nematode stages pipetted with sterile distilled $\mathrm{H} 2 \mathrm{O}$

2. Diluted out to desired numbers of nematodes $/ 1 \mathrm{ml}$

Assays conducted in sterile12-well tissue culture plates

$$
\begin{aligned}
& \text { 1. Gridlines } 2 \mathrm{~mm} \text { apart scratched on bottom of plates } \\
& \text { 2. } 1 \mathrm{~mL} \text { of mixed nematode stages } \\
& \text { 3. } 1 \mathrm{~mL} \text { aqueous filter sterilized alkaloid or fescue extracts at } \\
& \text { varying concentrations }
\end{aligned}
$$

Motile nematodes counted at $24 \mathrm{~h}$ increments

$$
\text { 1. Treatments are removed and replaced with fresh water }
$$$$
\text { 2. Allow nematodes } 24 \mathrm{~h} \text { to potentially recover }
$$

Motile nematodes counted and recorded 
Figure 2 Regression analysis of results of the bioassay of methanolic fractions of endophyte-infected tall fescue cv. Jessup total root extracts against Pratylenchus scribneri over 24 and 48 hour exposure periods. Fractions were significant at $\mathrm{P}<0.05$.

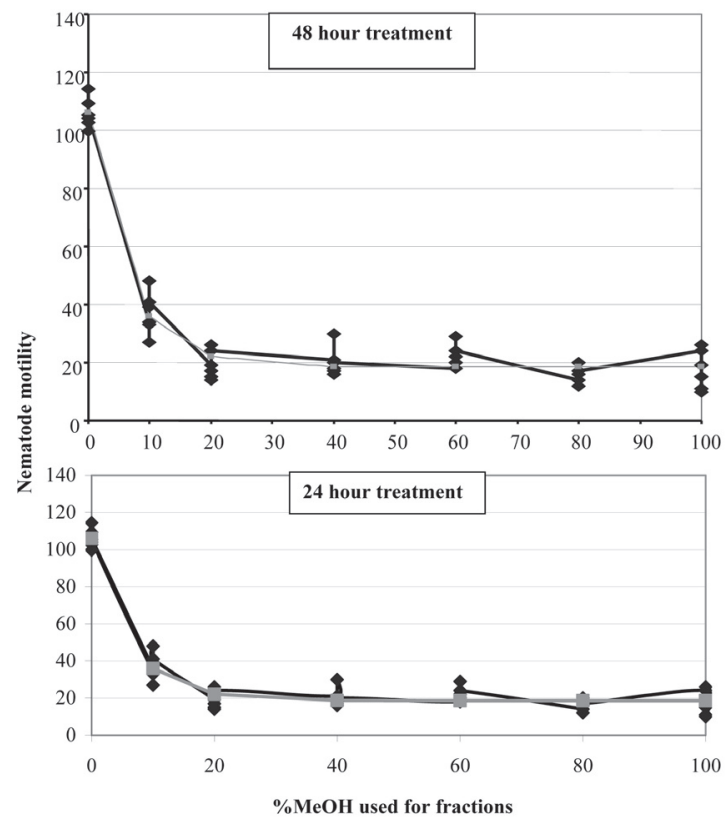

surface disinfected and the resulting $\mathrm{J} 2$ were maintained as sterile cultures on sterilised maize roots explants grown on Gamborg's BS medium (Nuettel \& Rebois 1985). All assays were conducted in sterile 12 -well polystyrene tissue culture plates incubated at $25^{\circ} \mathrm{C}$. One $\mathrm{ml}$ of $\mathrm{J} 2$ was added to each well (approximately 25 to $140 \mathrm{~J} 2 /$ well, depending on the experiment), followed by adding $1 \mathrm{ml}$ of sterile distilled water or buffer solution for control groups. Experimental groups contained appropriate dilutions of extracts in water. All experiments were tested with control treatments of water and solvents. The plates were incubated for $48 \mathrm{~h}$, after which all liquid was removed from the wells, and replaced immediately with fresh sterile water. The plates were incubated for an additional $24 \mathrm{~h}$, and motile nematodes were counted under low power of a dissecting microscope. It was observed that nematodes recovered their motility after $24 \mathrm{~h}$ in the fresh water rinse. Acute toxicity as defined here was a measure of the effects of compounds or fractions on the motility of secondstage juveniles of P. scribneri. Pratylenchus scribneri cultures were maintained in the greenhouse on roots of maize plants. All experiments were repeated four times and differences between endophyte-infected and non-infected extracts were significant with t-test (0.05).

\section{Preparation of plant extracts}

Endophyte infected and noninfected tall fescue, cv. Jessup, was grown in pot culture in the greenhouse. After 22 weeks, they were harvested, and the roots rinsed to remove soil. Plants were stored under refrigeration until analysis. Roots, $45 \mathrm{~g}$, were ground in $500 \mathrm{ml}$ of $100 \% \mathrm{MeOH}$ using a Polytron tissue grinder, filtered (Whatman \#2), and the $\mathrm{MeOH}$ evaporated under vacuum. The resulting residues were weighed and a stock solution made up in distilled water adjusted to produce extract solutions between 115 and 2,400 ppm. These solutions were filter sterilised $(0.2 \mu \mathrm{m})$ before use. The assays were conducted as indicated above.
Figure 3 HPLC chromatogram of a methanolic root extracts of endophyte I, and noninfected, II, tall fescue cv. Jessup. Key to peak identities: A, 3-caffeolyquinic acid, $B$ and $C$, unidentified caffeoylquinic isomers; D, 3,5dicaffeoylquinic acid; ISTD (internal standard), chrysin.

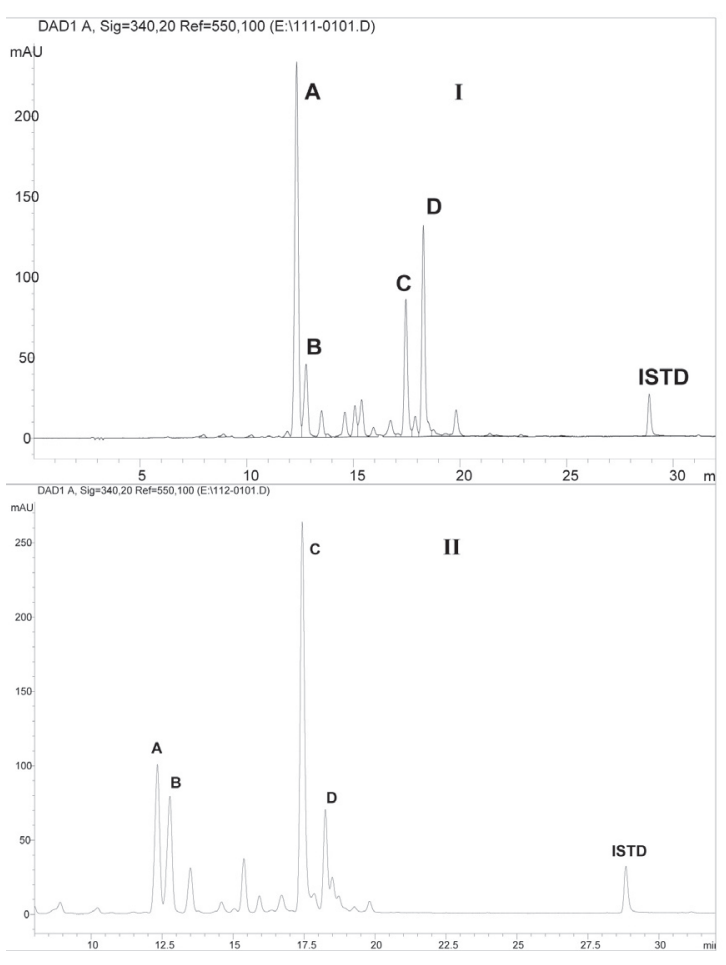

Identification of compounds.

Ergonovine, ergocornine, and $\alpha$-ergocryptine were purchased from Sigma, St Louis, MO, USA. The loline alkaloids were obtained as a mixture (n-acetyl loline and $\mathrm{N}$-formyl loline alkaloids), which was extracted from tall fescue seed. Identification of fractions in compounds were generated with an HP 1050 diode array, an HPLC linear gradient from 10\% $\mathrm{MeOH}$ in 35 min, using a Beckman Ultrtasphere ODS $\left(\mathrm{C}_{18}\right)$ column 2.5 x $250 \mathrm{~mm}$ with a UV detector at $350 \mathrm{~nm}$. The total root extract, 1 $150 \mathrm{ppm}$, was poured onto $\mathrm{a}_{18}$ column and 0, 10, 20, 40, 60, 80, and $100 \% \mathrm{MeOH}$ fractions were collected (Fig. 2). The $\mathrm{MeOH}$ was evaporated and water added to adjust each $\mathrm{MeOH}$ fraction back to approximately $1150 \mathrm{ppm}$. Experiments were repeated four times and differences between endophyte-infected and noninfected extracts were significant with t-test $(0.05)$.

\section{Results and Discussion}

HPLC and UV mass spectrometry analysis of root extracts revealed the presence of many polyphenolic substances of which the major compounds identified were chlorogenic and di-caffeoylquinic acids (Fig. 3). A concentration of $1150 \mathrm{ppm}$ was chosen as an optimal concentration for further testing of this methanolic fraction against the bioassay. The in vitro assay system revealed that methanolic root extracts and sub-fractions of $N$. coenophialum-infected tall fescue roots exhibited adverse effects on $P$. scribneri activity while non-infected root extracts did not show any signs of adverse activity on this nematode. 
Table 1 Bioassay of total root extracts of endophyte-infected and noninfected tall fescue cv. Jessup against motility of Pratylenchus scribneri scored at 24 and 48 hours. A total of $45 \mathrm{~g}$ of roots were used from 22 wk old pot grown plants. All experiments were replicated four times and results presented as an average. Differences between infected and noninfected fractions were significant at $\mathrm{P}=0.05$. See text for extraction protocol.

\begin{tabular}{lcccc}
\hline & \multicolumn{3}{c}{ Nematode Motility } \\
$\begin{array}{l}\text { Extract } \\
\text { concentration (ppm) }\end{array}$ & Noninfected & Infected & Noninfected & ---- 48 hours ---- \\
\hline 115 & 117 & 99 & 93 & 40 \\
287.5 & 105 & 95 & 85 & 21 \\
862.5 & 103 & 97 & 92 & 25 \\
1150 & 98 & 80 & 80 & 26 \\
1725 & 92 & 68 & 77 & 35 \\
2400 & 90 & 63 & 68 & 20 \\
\hline
\end{tabular}

Table 2 Bioassay of ergot and loline alkaloids on motility of Pratylenchus scribneri bioassayed 24 and 72 hours following exposure, measured in fresh water. All experiments were replicated four times and results presented as an average. Differences between infected and noninfected fractions were significant at $P=0.05$. See text for extraction protocol.

\begin{tabular}{|c|c|c|c|c|c|c|c|c|c|}
\hline \multirow[b]{3}{*}{ Treatments } & \multicolumn{9}{|c|}{ Motility } \\
\hline & \multirow[b]{2}{*}{ Control } & \multicolumn{2}{|c|}{$----5^{\star}----$} & \multicolumn{2}{|c|}{---- 50 ---- } & \multicolumn{2}{|c|}{---- 100 ---- } & \multicolumn{2}{|c|}{---- 250 ---- } \\
\hline & & $24 \mathrm{~h}$ & $72 \mathrm{~h}$ & $24 \mathrm{~h}$ & $72 \mathrm{~h}$ & $24 \mathrm{~h}$ & $72 \mathrm{~h}$ & $24 \mathrm{~h}$ & $72 \mathrm{~h}$ \\
\hline Loline & 29 & 8.25 & 2.5 & 3.5 & 0.25 & 0 & 0 & 0 & 0 \\
\hline Ergonovine & 29 & 5 & 4.75 & 4 & 2 & 2.5 & 1.25 & 1 & 0.25 \\
\hline Ergocornine & 29 & 13.25 & 9 & 12.5 & 8.25 & 12.5 & 6.25 & 12.25 & 4 \\
\hline$\alpha$-Ergocryptine & 29 & 9.25 & 2.5 & 4 & 1.75 & 0 & 0 & 0 & 0 \\
\hline
\end{tabular}

Within corresponding fractions from infected and noninfected root extracts, the differences were significant at $\mathrm{P}=0.05$. Motility of $\mathrm{J} 2$ was not recovered in any of the treatments after the extended observation period.

Healthy intact roots release into soils exudates containing hydrophobic and hydrophilic substances, including various classes of compounds such as organic acids, peptides, amino acids, sugars, phenols, and other miscellaneous compounds. The roots of grasses, tall fescue in particular, are noted producers of exudates that are speculated to be stimulatory, inhibitory, or inactive relative to competing organisms. Phenolic compounds are one such class that serves as deterrents of several soil pathogens and invertebrate pests (McKeehen et al. 1999; Wu et al. 2001). The water soluble phenolic acid fractions were established as biologically active in the nematode bioassay. Therefore, the phenolic acid fractions are candidate compounds potentially involved in resistance or tolerance to nematodes capable of parasitizing tall fescue.

The fungal endophyte $N$. coenophialum, associated with tall fescue, produces various secondary metabolites that are potentially toxic to nematodes. Increasing the exposure time of nematodes to total extracts from endophyte-infected roots resulted in decreased nematode motility. However nematode motility was not affected by exposure to extracts from the noninfected roots.

The results from this bioassay indicate that it is suitable for testing whole extracts of tall fescue, which we have shown contain natural metabolites that are toxic to P. scribneri (Table
1). The caffeoylquinic acid isomers are phenolic acids with known biological activity to many invertebrate pests, including nematodes (Wu et al. 2001). Interestingly, the production of phenolics has been reported in Epichloe typhina (Koshino et al. 1988). While the occurrence of the polyphenolics in tall fescue shows no qualitative difference relative to endophyte status, we show here that there is a quantitative difference. Endophyteinfected and non-infected roots had the same caffeoylquinic acid derived polyphenolics, but at varying concentrations. Based on an analysis of the HPLC peaks, chlorogenic acid in roots of endophyte-infected and noninfected was present at 558 and 339 ppm respectively. The caffeoylquinic acid isomer in endophyteinfected and noninfected tall fescue roots was found at 118 and $281 \mathrm{ppm}$ respectively, while the other unidentified caffeoylquinic acid isomer was present at 191 and 813 ppm respectively. The other polyphenolic acid, 3, 5-Dicaffeoylquinic acid, was present at 285 and $200 \mathrm{ppm}$ respectively, but the biological significance to these two differences relative to nematode activity has not been determined.

Three commercially available alkaloids, ergonovine, ergocornine, and $\alpha$-ergocryptine, were tested for toxicity to P. scribneri (Table 2). After $72 \mathrm{~h}$, nematode toxicity was only observed in those treatment groups exposed to ergocornine at concentrations higher than $50 \mu \mathrm{g} / \mathrm{ml}$. After the observation periods were completed, all liquid was removed and replaced with fresh sterile water. Motile nematodes were counted after 24 and $96 \mathrm{~h}$ following the water replacement. It was observed that nematode motility did not recover after $96 \mathrm{~h}$ rinse with ergonovine, and $\alpha-$ 
Table 3 Bioassay of combinations of ergot and loline alkaloids on the motility of Pratylenchus scribneri bioassayed at 24 and 72 hours following exposure, measured in fresh water. All experiments were replicated four times and results presented as an average. Differences between infected and noninfected fractions were significant at $P=0.05$. See text for extraction protocol

\begin{tabular}{|c|c|c|c|c|c|c|c|c|c|}
\hline \multirow[b]{3}{*}{ Treatments } & \multicolumn{9}{|c|}{ Motility } \\
\hline & \multirow[b]{2}{*}{ Control } & \multicolumn{2}{|c|}{---- 10* ---- } & \multicolumn{2}{|c|}{---- 50 ---- } & \multicolumn{2}{|c|}{---- 100 ---- } & \multicolumn{2}{|c|}{---- 250 ---- } \\
\hline & & $24 \mathrm{~h}$ & $72 \mathrm{~h}$ & $24 \mathrm{~h}$ & $72 \mathrm{~h}$ & $24 \mathrm{~h}$ & $72 \mathrm{~h}$ & $24 \mathrm{~h}$ & $72 \mathrm{~h}$ \\
\hline Loline + ergocornine & 21 & 3.5 & 0.25 & 0.25 & 0 & 0.25 & 0 & 0 & 0 \\
\hline Loline $+\alpha$-ergocryptine & 21 & 5.5 & 1.25 & 0 & 0.75 & 0 & 0 & 0 & 0 \\
\hline Ergocornine $+\alpha$-ergocryptine & 21 & 6.5 & 0.25 & 4 & 0 & 0.5 & 0 & 0 & 0 \\
\hline Loline $+\alpha$-ergocryptine + ergocornine & 21 & 2.25 & 0 & 0 & 0 & 0 & 0 & 0 & 0 \\
\hline
\end{tabular}

ergocryptine. However, the nematodes exposed to ergocornine either remained motile or regained motility in numbers similar to control groups.

Experiments designed to determine potentiating and or synergistic effects of the previously tested alkaloids involved mixing positive ergot alkaloid with the loline alkaloids at various concentrations (Table 3). Assays were conducted as described in sterile 12-well polystyrene tissue culture by adding $1 \mathrm{ml}$ (approximately $25 \mathrm{~J} 2 /$ well) and $1 \mathrm{ml}$ of an alkaloid mixture. After 72 h, J2 motility was greatly decreased over those observed when each compound was used alone. At $10 \mu \mathrm{g} / \mathrm{ml}$, the loline + $\alpha$-ergocryptine mix had an average of 1.25 motile $\mathrm{J} 2$ and at $50 \mu \mathrm{g} /$ $\mathrm{ml}$ there was an average of 0.75 motile $\mathrm{J} 2$ was observed. At 10 $\mu \mathrm{g} / \mathrm{ml}$ the loline + ergocornine and ergocornine $+\alpha$-ergocryptine mixtures had an average of $25 \%$ motile J2. All experimental liquids were removed and replaced with fresh sterile water, where motility observations were conducted over a 24 to $96 \mathrm{~h}$ post exposure period.

The results of tests on purified alkaloids indicate that there is toxicity in specific ergot alkaloids along with the loline alkaloids. Based on this in vitro bioassay two of the ergot and loline alkaloids are acutely toxic to this species of lesion nematode. The toxicities recorded were nematocidal and not static responses since water rinses did not restore nematode motility after a 96 hours extended observation period. This is particularly interesting since these fungal secondary metabolites occur in symbiotic tall fescue as a mixture, suggesting that high concentrations in tall fescue are not necessary to kill this lesion nematode. However, the in planta distribution suggests that the ergot alkaloids are present in root tissue at low concentrations, if at all. Thus, the potentiating effects with the lolines alkaloids are strongly suggestive of a probable mechanism for P. scribneri inhibition. The results of this study indicate that further testing of these compounds, alone and in combinations with additional alkaloids and the phenolics are warranted. These compounds will be further investigated, along with ergovaline, the principle ergot alkaloid found in symbiotic tall fescue, for their potential individual and synergistic activities against $P$. scribneri and ultimately other nematode species.

\section{Conclusion}

The in vitro bioassay described can be used to detect acute toxicities of compounds and fractions from tall fescue to $P$. scribneri, a nematode that is parasitic on tall fescue. Although its action on nematode reproduction is not assessed by the assay, the results can be used as an indirect measure of reproductive toxicity by recording the effects on nematode egg hatch (Meyer et al. 1990). The assay is rapid, allowing the testing of specific purified compounds for nematode toxicity, but also identifying grass or fungal crude extracts for more detailed chemical examinations. This assay can also be used for several other nematode species associated with tall fescue, including species of Meloidogyne, Heterodera, and Xiphinema (Nitao et al. 1999). The results indicate that while constituents within the ergot alkaloid fraction are toxic to this species of nematode, there are possible potentiating effects observed when other alkaloids are mixed, suggestive of prior observations of toxicity on specific insects (Siegel et al. 1991). Further, total phenolic and specific phenolic contents were determined in roots of endophyte infected and noninfected tall fescue cv. Jesup. HPLC analysis and UV mass spectrometry of root extracts revealed the presence of two major polyphenolics that were identified as chlorogenic and di-caffeoylquinic acids, both of which have known toxicity to several species of nematodes. Correlations of in planta nematode toxicity with this bioassay are warranted, as well as detailed studies on specific and relevant ergot alkaloids and other phytotoxins known to occur in roots of tall fescue.

\section{REFERENCES}

Ciancio, A. 1995. Observations on the nematicidal properties of some mycotoxins. Fundamental of Applied Nematology 18: 451-454.

Halisky, P.M.; Myers, R.F. 1989. Effect of Acremonium endophytes on parasitic nematodes in Festuca and Lolium grown under turf maintenance. pp. 124-131. In: Rutgers Turfgrass Proceedings. Rutgers University, New Brunswick, N.J.

Hoveland, C.S.; Rodriguez-Kabana, R.; Berry, C.D. 1975. Phalaris and tall fescue forage production as affected by nematodes in the field. Agronomy Journal 67: 714-717.

Koshino, H.; Terada, S.; Yoshihara, T.; Sakamura, S.; Shimanuki, T.; Sato, T.; Tajimi, A. 1988. Three phenolic acid derivatives from stromata of Epichloe typhina on Phleum pratense. Phytochemistry 27: 1333-1338.

McGowan, P.J.; Sasser, J.N.; Sherwood, R.T. 1961. Investigations of plant-parasitic nematodes associated with forage crops in North Carolina. North Carolina State University Experiment Station Technical Bulletin. Plant Disease 148: 1-39.

McKeehen, J.D.; Busch, R.H.; Fulcher, R.G. 1999. Evaluation of wheat (Triticum aestivum L.) phenolic acids during grain development and their contribution to Fusarium resistance. 
Journal Agricultural Food Chemistry 47: 1476-1482.

Meyer, S.L.F.; Huettel, R.N.; Sayre, R.M. 1990. Isolation of fungi from Heterodera glycines and in vitro bioassays for their antagonism to eggs. Journal of Nematology 22: 532-537.

Nitao, J.K.; Meyer, S.L.F; Chitwood, D.J. 1999. In vitro assays of Meloidogyne incognita and heterodera glycines for detection of nematode-antagonistic fungal compounds. J. Nematology 31: 172-183.

Nitao, J.K.; Meyer, S.L.F.; Schmidt; W.F.; Fewson, C.A.; Chitwood, D.J. 2001. Nematode-antagonistic trichothecenes from Fusarium equiseti. Journal of Chemical Ecology 27: 859-869.

Nuettel, R.N.; Rebois, R.V. 1985. Culturing plant-parasitic nematodes using root explants. pp. 155-158. In: Plant Nematology Laboratory Manual. Eds. Zuckerman, B. M.; Mai, W. F.; Harrison, M. B. University of Massachusetts Agricultural Experiment Station, Amherst, MA.

Pedersen, J.F.; Rodriguez-Kabana, R.; Shelby, R.A. 1988. Ryegrass cultivars and endophyte in tall fescue affect nematodes in grass and succeeding soybean. Agronomy Journal 80: 811-814.

Pederson, J.F.; Rodriguez-Kabana, R. 1984. Differences among nematode populations in tall fescue pastures in north, central, and south Alabama. Crop Science 24: 819-821.
Siegel, M.R.; Latch, G.C.M.; Bush, L.P., Fannin; N.F., Rowen; D.D., Tapper, B.A.; Bacon, C.W.; Johnson, M.C. 1991. Alkaloids and insecticidal activity of grasses infected with fungal endophytes. Journal of Chemical Ecology 16: 3301-3315.

Townsend, W.E.; Cline, R.A.; Dirks, V.A.; Marks, C.F. 1984. Assessment of turfgrasses for the management of Pratylenchus penetrans and Pratylenchus projectus. Canadian Journal of Plant Science 64: 355-360.

West, C.P.; Izekor, E.; Oosterhuis, D.M.; Robbins, R.T. 1988. The effects of Acremonium coenophialum on growth and nematode infestation of tall fescue. Plant and Soil 112: 3-6.

West, C.P.; Izekor, E.; Robbins, R.T.; Gergerich, R.; Mahmood, T. 1990. Acremonium coenophialum effects on infestations of barley yellow dwarf virus and soil-borne nematodes and insects in tall fescue. pp. 196-198. In: Proceeding International symposium on Acremonium/Grass Interactions. Eds. Quisenberry, S.; Joost, R. E., November 5-6: Louisiana Agricultural Experiment Station, Baton Rouge, LA.

Wu, H.W., Haig, T.; Pratley, J.; Lemerle, D.; An, M. 2001. Allelochemicals in wheat (Triticum aestivum L.): Cultivar difference in the exudation of phenolic acids. Journal of Agricultural and Food Chemistry 49: 3742-3745. 